San Jose State University

From the SelectedWorks of Lili Luo

March, 2015

\title{
JAL in the Past Decade: A Comprehensive Analysis of Academic Library Research
}

Lili Luo, San Jose State University

Margaret McKinney 


\title{
JAL in the Past Decade: A Comprehensive Analysis of Academic Library Research
}

\author{
Lili Luo \& Margaret McKinney
}

\begin{abstract}
:
A content analysis is conducted to examine the peer-reviewed articles published in the Journal of Academic Librarianship (JAL) from 2004 to 2013. Five key variables are studied: authorship, article type, topic, research methods/design, and research theories/models. About three-fourths of the articles were authored by at least one librarian, and over half of the articles were co-authored. More than two-thirds of the articles were primary research articles, and a total of 24 topics related to academic libraries were covered, among which information literacy was the most popular one. Survey and content analysis are the two most frequently used research methods in the articles. This study, capturing the topical and methodological substance of academic library research, will generate ideas for providing effective research training/education for academic librarians and contribute to the enhancement of research culture and research practice among them.
\end{abstract}

Keywords:

Academic libraries, academic librarians, research, research methods, content analysis

[This is the preprint. Please cite it as "Luo, L. \& McKinney, M. (2015). JAL in the past decade: A comprehensive analysis of academic library research. Journal of Academic Librarianship, 41(2), 123129."] 


\section{Introduction}

In a rapidly changing world where continuous learning and adapting is an inescapable fact of professional life, research is no longer an exclusive privilege held by the domain of the academy but part of the working world. Jarvis (1999) observed that research is now about "seeking, in a most rigorous manner, to understand and create efficient working practice" (p. xi), leading to a rising number of practitioner-researchers who undertake their own research to meet "the need for more information for use in decision making at the managerial level, the need to keep abreast of new knowledge and procedures in this information society, and the need for continuing education and upgraded qualifications" (p. 7).

In library and information science (LIS), the importance of research to practice has been well acknowledged. Research serves to create new knowledge and therefore contribute to the growth of LIS as a profession. It is needed to "improve problem solving and decision making in the workplace, to make professional practitioners critical consumers of the research literature, and to better equip librarians to provide optimal information services to researchers in other fields" (Powell, Baker \& Mika, 2002, p. 50). In LIS, numerous studies have attested to the importance of research in the advancement of the profession. Abundant literature suggests that research skills play an important role in librarians' work such as reference consultations, information literacy instruction, evaluation and management, and promotion and tenure (Bodi, 2002; Fister, 1992; Fister, 1993; Lenox, 1985; Perkins \& Helbig, 2008). Hernon and Schwartz (1995) summarized that research "can and should provide insights and guidance into how well library programs, services, and collections function, especially in making libraries more responsive service organizations" (p. 102).

In academic libraries, research and scholarship is emphasized. As early as 1972, ACRL's "Joint Statement on Faculty Status of College and University Librarians" highlighted librarians' research roles in both professional interests and work responsibilities (Perkins \& Slowik, 2013). Recently, the most influential federal funding agency in LIS, Institute of Museum and Library Services (IMLS), has funded a three-year program titled "Institute of Research Design for Librarianship (IRDL)", which provides continuing education opportunities for academic librarians to enhance their research skills and output, and to increase the scope and value of academic library research (IMLS, 2013). Given the wellacknowledged significance of research in academic libraries, it is important to understand how academic librarians are engaged in research to enhance their professional practice. Such an understanding can be achieved through close examination of the topics and methods of published research on problems and issues germane to academic libraries. Toward that aim, this study presents an in-depth analysis of the research articles published in the Journal of Academic Librarianship (JAL) in the past decade, seeking to capture the topical and methodological substance of academic library research and generate ideas for providing effective research training/education for academic librarians. 


\section{Literature review}

\subsection{Value of academic library research}

The value of research in academic libraries is well-documented in the literature. Perkins and Slowik (2013) reviewed ACRL's "Standards for College Libraries" in the past half-century, and pointed out that the professional standards have clearly confirmed the importance of inquiry and research activities such as scholarly publication, presentation of papers and reviews of books, and set the line for determining research quality of academic librarians so that their world could be more easily translatable to the academic community as a whole.

Montanelli and Stenstrom (1986) specified that the value of research for academic librarians included job promotion, personal acknowledgement, enriched relationships with teaching faculty, increased ability to change, and better library service through shared knowledge and experience. Similarly, through a study of scholarly e-journals, DuBose and Durant (2001) noted that the advantages of research for academic librarians included delineation of research subjects, collaboration with others, improved understanding and application to daily issues, and their own changing development as librarians. Perkins and Slowik (2013) interviewed 23 academic library administrators regarding their perceived value of research in their university/college libraries. Their findings echoed the literature, and the benefits of librarians' research identified in their study included fulfilling tenure-track requirements, library faculty recognition, improved services and programs, and improved knowledge of the research field.

Stewart, in two of his Metrics column articles for JAL (Stewart, 2010; 2011) discussed the importance of monitoring publication patterns in academic library research. He stated that "New levels of practitioner-driven scholarship and research will advance our evolving work while chronicling our achievements. Tracking this output is crucial and will enable us to quantify our impact on each other's work and research, our institutions, and even those in other disciplines" (Stewart, 2010, p. 453). One popular method to examine research output is content analysis. In the next section of the literature review, relevant content analysis studies are reviewed to provide a concrete understanding of how this method has been used to analyze academic librarians' research productivity.

\subsection{Content analysis studies}

While there has been a sizable amount of literature examining LIS research publications in general, only a limited number of content analysis studies focus on the contributions of academic librarians to the peer-reviewed literature in LIS. A review of these studies shows that the following variables are commonly investigated when analyzing academic librarians' research publications:

- Authorship. As one of the earliest studies that analyzed academic librarians' publication patterns, Krausse and Sieburth (1985) examined the authorship of twelve LIS journals between 1973 and 1982. Findings showed a steady increase in the percentage written by academic librarians. The range was between $28 \%$ and $42 \%$. While the productivity of these authors ranged from one to fourteen articles each, $78 \%$ of the librarians published only one article in the time period. Librarians' affiliations were divided into five classes ranging from smallest, with holdings of less than 100,000 volumes, to largest, with holdings of one million and more volumes, and more authors came from the larger libraries. Watson (1985) examined eleven LIS 
journals from 1979 to 1983, where 44.2\% of the authors were academic librarians. In addition, she identified the institutional affiliations of the authors, because "Publications by librarians at academic libraries is seen as an indication of an innovative, progressive library environment. The identification of the libraries in which it takes place may serve as an aid to job seekers in the academic library market" (p. 340). Budd and Seavey (1990) analyzed the authorship of 36 LIS journals from 1983 to 1987, and their findings were consistent with Krausse and Sieburth (1985) - the majority of the academic librarian authors were unique authors. They not only identified the authors' institutions, but also ranked individual authors based on their productivity. Two later studies conducted similar content analysis of LIS journals from 1993 to 1997, and from 1998 to 2002, respectively (Weller, Hurd and Wiberley, 1999; Wiberley, Hurd \& Weller , 2006). In addition to determining the percentage of articles authored by academic librarians and their institutional affiliations, the studies also ascertained co-authorship patterns in terms of the number of coauthors and the type of collaborators (e.g. faculty, non-academic librarians, library support staff). On average, $41 \%$ of refereed articles had at least one academic librarian author. Hart (2007) further investigated co-authorship via the analysis of citation counts to articles from two important journals of academic librarianship over a ten-year period, and his findings refuted the assumption that co-authorship results in a higher quality article. In recent years, researchers in Africa have taken an interest in academic librarians' research output, and two studies (Sitienei \& Ocholla, 2010; Ocholla, Ocholla \& Onyancha, 2012) conducted inquiries on similar authorship variables among academic librarian authors in eastern and southern Africa.

- Article type. Different types of articles are published in research journals, and some publishers have a list of predefined article classifications for authors to choose from. Mahraj (2012) analyzed five years' worth of articles in Reference Services Review, a popular reference-focused journal among academic librarians, and found that out of the eight publisher-defined article types, the top three were case study (31\%), literature review (22\%), and conceptual papers (15\%).

- Topic. The topical area of an article has been analyzed using two approaches - relying on the subject descriptors provided by databases where the articles are indexed, and developing a coding scheme to manually examine the article topics. Using the first approach, Ocholla, Ocholla and Onyancha (2012) found that the most popular subject descriptors used for articles published by academic librarians in east African was "Tanzania" and "University libraries", where were not able to convey the specific topic the articles focused on. The second approach, though more laborious, would produce more meaningful results. Mahraj (2012) and Sitienei and Ocholla (2010) both manually coded the article topics. However, in both studies, the coding process and the topical codes were minimally explained, making it difficult to interpret the results. For example, in Sitienei and Ocholla's (2010) study, they merely stated that the most published topic was information technology, without elaborating on what it entails.

The review of the above studies shows that the focus of the previous literature examining academic librarians' research output has been primarily on authorship. The other variables such as article type or topic have not been rigorously investigated. Furthermore, one important variable, research methods used in the study, is completely lacking. Using appropriate methods to gather data and analyze data is 
key to successfully producing valid and reliable evidence to improve professional practice. Thus, it is important to understand the methods academic librarians use in their research studies. Such an understanding will yield better-designed education/training programs to help them enhance their research confidence and competence, and engage in more methodologically sound research activities. This study seeks to fill the void in the literature through a content analysis that examines not only authorship, but also other critical variables such as article topic and research methods in academic librarians' publications.

\section{Methodology}

The unobtrusive research method, content analysis, was used to examine research articles published in JAL from 2004 to 2013. JAL was chosen because it is one of the important journals about academic library research, and JAL articles are representative of academic librarians' contribution to LIS literature. A total of 541 peer-reviewed research articles were published in the 59 issues ranging from 2004 to 2013, which constituted the data set for this study. Non-peer-reviewed publications such as editorials, book reviews, and column articles were excluded from the study.

The analysis focused on the following variables: article type, authorship, topic, research methods/design, and theories/models. For each variable, a coding scheme was developed and the articles were coded accordingly. Inductive and deductive coding alternated in the process. A small sample of articles were coded inductively to develop the initial coding scheme, which was then refined as it was applied to deductively code the rest of the articles.

\section{Results}

\subsection{Article type}

Depending on whether or not primary research was conducted, the articles were grouped into three categories:

1. Primary research articles. Primary research involves the collection, analysis and synthesis of original, primary data to answer a research question. The researcher may use various research methods such as survey, focus group interview, and content analysis to gather and analyze data in primary research. The majority of the articles, $64.0 \%$, were primary research articles. Some of the studies (29.1\%) had an institutional focus and data was collected only from a single institution - e.g. surveying biology students at a university to examine their perception and knowledge of scientific literature (Bandyopadhyay, 2013), and conducting bibliometric analysis to examine the citation behavior of aerospace engineering faculty at a university (Stephens, Hubbard, Pickett, \& Kimball, 2013). The remaining studies (34.9\%) were not restrained by a single institutional setting, and had a more diverse study population. For instance, analyzing job advertisements from 1970 to 2010 to study job duties of distance education librarians (Tang, 2013), and surveying all librarians in Pennsylvania about the mentoring practice (Neyer \& Yelinek, 2011).

2. Descriptive articles about a project, a situation, a movement, the history or current state of an entity or a phenomenon. About one-fifth of the articles (20.5\%) fall under this category - e.g. describing the development and implementation of an academic integrity course (Greer, 
Swanberg, Hristova, Switzer \& Daniel, 2012), describing the situation of librarian outsourcing in Japan (Matsuoka-Motley, 2011), and introducing the process of developing a collections-based mobile way finding app (Hahna \& Morales, 2011).

3. Essays that offer a comparative, summative, reflective, or conceptual view on a certain topic. Only $15.5 \%$ of the articles were such essays. Examples include a literature review on the changing role of academic librarians (Shupe \& Pung, 2011), a position paper on connecting the social Web to ACRL learning outcomes (Bobish, 2011), and an essay comparing Elsevier Compendex and Google Scholar as resources for engineering research (Cusker, 2013).

\subsection{Authorship}

Among the 541 peer-reviewed articles, $45.7 \%$ were single authored, and $54.3 \%$ had multiple authors. Figure 1 represents the distribution of the number of authors for the articles.

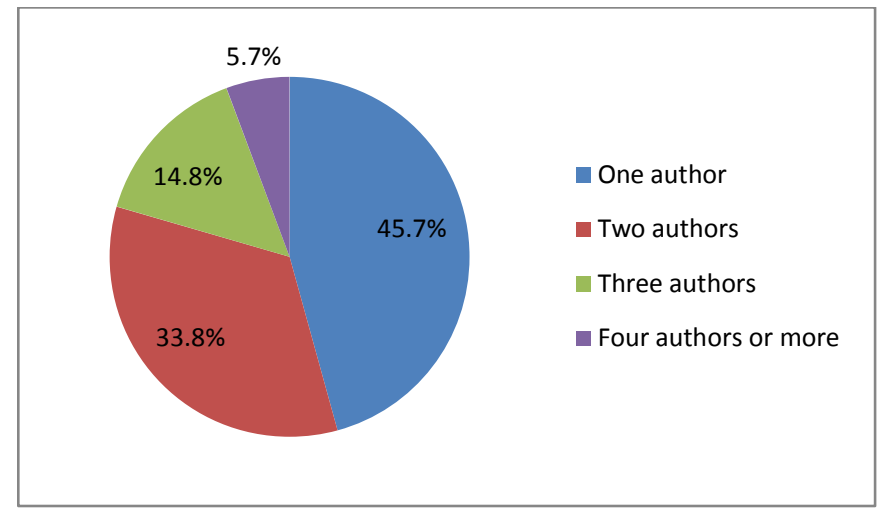

Figure 1. Number of authors for the articles

Table 1 shows the status of the authors. Among the single authors, the majority were librarians (74.5\%). It is also worth noting that faculty from non-LIS disciplines were publishing in JAL, suggesting that library-related topics are of interest to researchers outside of LIS. Among the coauthored articles, more than half were authored by collaborating librarians, and a little over one-fourths were results of research partnerships between librarians and non-librarians (e.g. faculty). Meanwhile, $62.2 \%$ of the coauthors were from the same institution, and $37.8 \%$ were from different institutions.

\begin{tabular}{|c|c|c|}
\hline \multirow{5}{*}{ Single Authors } & \multicolumn{2}{|l|}{$\mathrm{N}=247$} \\
\hline & Librarian & $74.5 \%$ \\
\hline & LIS faculty & $17.4 \%$ \\
\hline & $\begin{array}{l}\text { Non-LIS faculty (faculty in non-LIS disciplines such as business } \\
\text { and education) }\end{array}$ & $1.6 \%$ \\
\hline & $\begin{array}{l}\text { Other, including LIS students, and individuals affiliated with LIS- } \\
\text { related organizations, corporations, or academic/government } \\
\text { units }\end{array}$ & $6.5 \%$ \\
\hline \multirow{4}{*}{ Multiple Authors } & \multicolumn{2}{|l|}{$\mathrm{N}=294$} \\
\hline & All librarians & $52.0 \%$ \\
\hline & Librarians and non-librarians & $25.2 \%$ \\
\hline & All non-librarians & $22.8 \%$ \\
\hline \multirow{3}{*}{ Author institution } & \multicolumn{2}{|l|}{$\mathrm{N}=294$} \\
\hline & Coauthors are all from the same institution & $62.2 \%$ \\
\hline & Coauthors are from different institutions & $37.8 \%$. \\
\hline
\end{tabular}


Table 1. Author status.

Regarding the geographic location of the authors, $78.7 \%$ of the articles were published by authors from North America, 9.8\% Asia, 6.3\% Europe, 1.7\% Oceania, 1.3\% Africa, and the remaining 2.2\% had authors from multiple continents.

\subsection{Topic}

The articles were grouped into 24 categories in terms of their topical coverage. Table 1 presents the break-down of the topics, for each of which, a detailed description is provided. The most popular topic was information literacy, and a little over one fifth of the articles were about issues related to different aspects of information literacy. The least popular topic was data service and only $0.2 \%$ of the articles fell under this category. The minimal presence of this topic can be attributed to the nascent nature of data service. It is still an emerging area in academic librarianship.

\begin{tabular}{|c|c|c|}
\hline Topic & Description & $\%$ \\
\hline Information literacy & $\begin{array}{l}\text { Issues related to different aspects of information literacy, such as instruction, assessment, } \\
\text { perceptions, attitudes, interpretation, and skills. }\end{array}$ & 20.9 \\
\hline $\begin{array}{l}\text { User information } \\
\text { behavior and } \\
\text { implications for library } \\
\text { service }\end{array}$ & $\begin{array}{l}\text { Information behavior refers to how people need, seek, manage, give and use information in } \\
\text { different contexts. Indicators of Information behavior include (but are not limited to) information } \\
\text { access, information seeking behavior, information needs, information values, and information use. } \\
\text { Library users consist of various groups such as undergrad students, graduate students, faculty and } \\
\text { researchers from different disciplines, and special populations like alumni, LGBT students, } \\
\text { international students, visiting scholars, and students of a particular ethnic group. Articles grouped } \\
\text { in this category also cover factors impacting library users' information behavior (e.g. tenure status } \\
\text { of faculty, student housing, etc.). }\end{array}$ & 11.3 \\
\hline Library personnel & $\begin{array}{l}\text { Issues related to library personnel. Three subtopics are included in this category: 1) hiring of library } \\
\text { personnel; 2) professional development needs and activities/opportunities, and administrative } \\
\text { support for professional development; and 3) library personnel's professional experiences, such as } \\
\text { their identity/status, job satisfaction, expectations, perceptions of job responsibilities, and career } \\
\text { paths. }\end{array}$ & 9.4 \\
\hline $\begin{array}{l}\text { Scholarly } \\
\text { communications }\end{array}$ & $\begin{array}{l}\text { Issues related to different aspects of scholarly communications, including scholarly publishing/open } \\
\text { access, analysis of published literature in a particular subject area using bibliometric methods (e.g. } \\
\text { citation analysis), and institutional/subject repositories. }\end{array}$ & 8.7 \\
\hline E-resources & $\begin{array}{l}\text { Issues related to e-journals and e-books, including (but not limited to) usage, evaluation, } \\
\text { management, and system. }\end{array}$ & 6.1 \\
\hline Library collections & $\begin{array}{l}\text { Management, development, and evaluation of different types of library collections, including special } \\
\text { collections. }\end{array}$ & 5.9 \\
\hline $\begin{array}{l}\text { Organization and } \\
\text { management }\end{array}$ & $\begin{array}{l}\text { Elements of organization and management, such as budget and spending, staffing, and } \\
\text { organizational culture. }\end{array}$ & 4.6 \\
\hline $\begin{array}{l}\text { Library reference } \\
\text { service }\end{array}$ & Issues related to different aspects of library reference service. & 4.4 \\
\hline $\begin{array}{l}\text { Planning and } \\
\text { assessment }\end{array}$ & $\begin{array}{l}\text { Issues related to planning and assessment in academic libraries. Articles on assessment cover two } \\
\text { subtopics: 1) outcomes of assessment/what is being assessed (e.g. quality of library services; } \\
\text { library's impact on campus learning culture); } 2 \text { ) methods of assessment/how to assess (e.g. LibQual) }\end{array}$ & 4.3 \\
\hline $\begin{array}{l}\text { Review and } \\
\text { conceptualization of } \\
\text { academic libraries }\end{array}$ & History, current status, and future development of academic libraries in different countries. & 3.1 \\
\hline $\begin{array}{l}\text { Information } \\
\text { organization }\end{array}$ & $\begin{array}{l}\text { Organization of information, including cataloging, indexing, folksonomy and other methods of } \\
\text { organizing information. }\end{array}$ & 3.0 \\
\hline $\begin{array}{l}\text { Library Website and } \\
\text { Web services }\end{array}$ & Design, usability, and content of library Website and various Web services. & 3.0 \\
\hline New technologies & Use of technologies, especially new technologies in academic libraries & 2.8 \\
\hline $\begin{array}{l}\text { Innovative or unique } \\
\text { library }\end{array}$ & $\begin{array}{l}\text { Library programs/services that are not traditionally provided, e.g. offering fee-based consultation } \\
\text { service, collaborating with virtual organizations in developing tags, librarians providing advising to }\end{array}$ & 2.4 \\
\hline
\end{tabular}




\begin{tabular}{|l|l|l|}
\hline programs/services & $\begin{array}{l}\text { students, and linking library resources into the learning management system using a toolkit } \\
\text { approach. }\end{array}$ & \\
\hline Digital services & Issues related to digital collections, digital libraries and efforts of digitization. & 1.8 \\
\hline Spaces and facilities & Design, use and evaluation of library spaces and facilities. & 1.7 \\
\hline $\begin{array}{l}\text { Systems and technical } \\
\text { services }\end{array}$ & $\begin{array}{l}\text { Issues related to different aspects of systems and technical services, such as interlibrary loan (ILL), } \\
\text { document delivery, OPAC, integrated library system (ILS), and circulation. }\end{array}$ & 1.7 \\
\hline $\begin{array}{l}\text { Collaboration between } \\
\text { libraries }\end{array}$ & Issues related to library consortia, networks and other forms of collaboration between libraries. & 1.1 \\
\hline $\begin{array}{l}\text { Legal issues } \\
\text { Librarian-faculty } \\
\text { relationship }\end{array}$ & Copyright, patron privacy and other legal issues in academic libraries. & 1.1 \\
\hline Outreach & Issues related to the relationship between librarians and faculty. & 0.9 \\
\hline LIS education & Education of LIS professionals in degree programs. & 0.9 \\
\hline $\begin{array}{l}\text { Librarians' research } \\
\text { activities and output }\end{array}$ & Librarians' engagement in conducting and producing research. & 0.7 \\
\hline Data service & Services related to data management. & 0.7 \\
\hline
\end{tabular}

Table 2. Article topics

To understand the topical trend over the years, a comparative analysis was conducted to examine the number of articles published each year in the top four categories - information literacy, user information behavior and implications for library services, library personnel, and scholarly communications. As shown in figure 2 , the only visible trend seems to be the spike of articles in scholarly communications in 2013. This spike could be explained by the 2013 special issue in open access, in which all the peer reviewed articles were related to digital scholarly publishing.

Since the most popular topic, information literacy instruction, often involves collaboration between librarians and faculty, a correlational analysis was conducted to examine if articles on this topic are more likely to be coauthored. Pearson's correlation coefficient $r$ was used in the analysis and the resulting value was .46, showing a moderately positive relationship between information literacy and coauthorship.

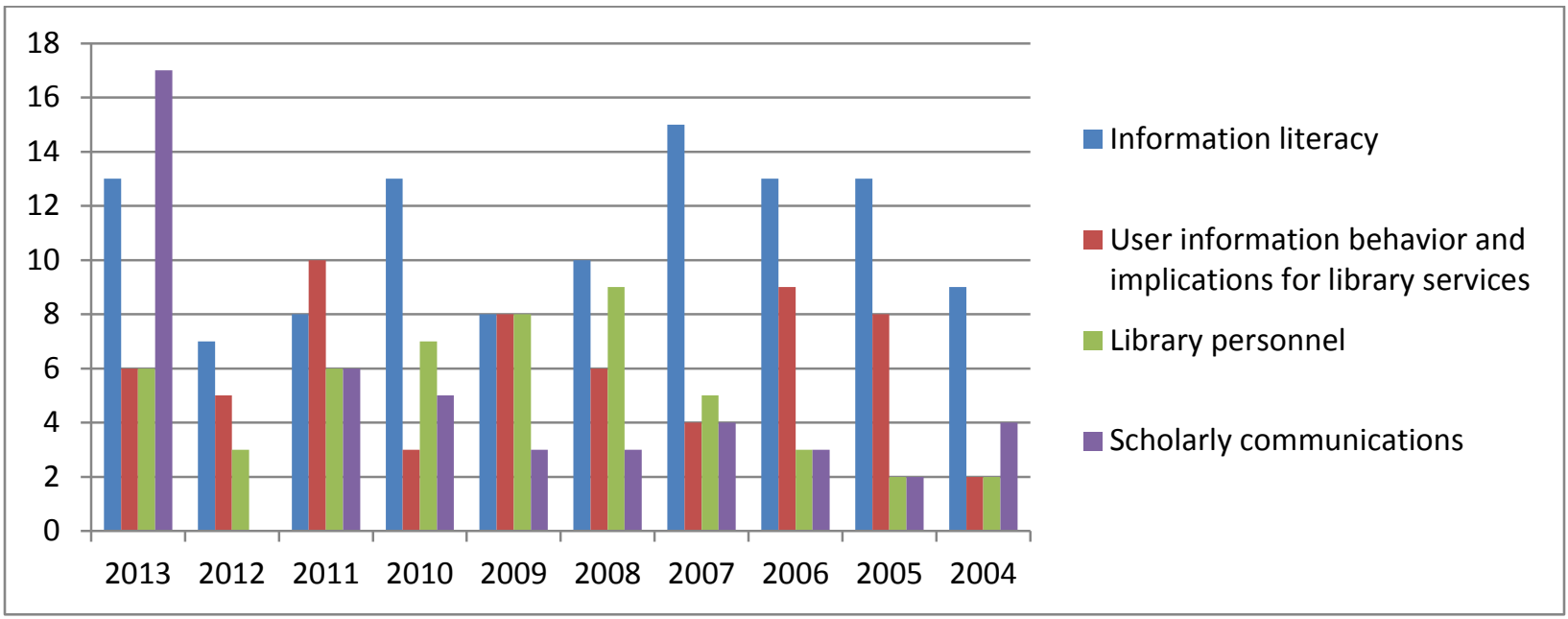

6. Figure 2. A comparative analysis of the top 4 topics

\subsection{Research methods}

In this study, research methods are defined as specific methods and techniques employed to collect and analyze data in a research study. For each primary research article, its research methods were identified and an aggregated view is presented in Table 3. One article may use more than one research 
method. A wide variety of research methods were used, and the most popular one was survey questionnaire.

\begin{tabular}{|c|c|c|}
\hline \multicolumn{2}{|c|}{ Research method } & $\%$ of primary research articles \\
\hline \multirow[t]{3}{*}{ Questionnaire } & $\begin{array}{l}\text { A standard survey } \\
\text { questionnaire }\end{array}$ & 47.6 \\
\hline & $\begin{array}{l}\text { A test or quiz in the } \\
\text { questionnaire format, usually } \\
\text { used in experimental or quasi- } \\
\text { experimental deign }\end{array}$ & 2.6 \\
\hline & $\begin{array}{l}\text { Diary, a type of self- } \\
\text { administered questionnaire } \\
\text { often used to record frequent } \\
\text { or contemporaneous events or } \\
\text { experiences }\end{array}$ & 0.6 \\
\hline \multicolumn{2}{|r|}{ Content analysis } & 27.2 \\
\hline \multicolumn{2}{|c|}{ Semi-structured or in-depth interview } & 14.0 \\
\hline \multicolumn{2}{|c|}{$\begin{array}{l}\text { Analysis of existing statistics (e.g. results from } \\
\text { previous surveys, or circulation statistics) }\end{array}$} & 6.6 \\
\hline \multicolumn{2}{|c|}{ Citation analysis } & 6.3 \\
\hline \multicolumn{2}{|c|}{ Focus group interview } & 5.7 \\
\hline \multicolumn{2}{|c|}{$\begin{array}{c}\text { Observation, including both quantitative and } \\
\text { qualitative observation }\end{array}$} & 4.3 \\
\hline \multicolumn{2}{|c|}{ Log analysis } & 3.4 \\
\hline \multicolumn{2}{|c|}{$\begin{array}{l}\text { Task analysis - the analysis of the completion of } \\
\text { search tasks }\end{array}$} & 2.9 \\
\hline
\end{tabular}

Table 3. Research methods used in the primary research articles (each article may have used more than one research method).

Research design refers to a systematic plan to study a research problem. Not all primary research studies were conducted using a particular type of research design. Only a total of forty-two articles specifically mentioned the use of a research design in guiding data collection and analysis, as shown in Table 4.

The research design typology is as follows:

- Time dimension - cross-sectional and longitudinal. A cross-sectional study is based on observations representing a single point in time. A longitudinal study involves the collection of data at different points in time (Babbie, 2012).

- Degree to which research variables are manipulated - experimental and quasiexperimental. In an experimental study, one or more independent variables are deliberately changed in order to observe the effect the changes have on one or more dependent variables. A classic or true experiment involves three major pairs of components: 1 ) independent and dependent variables; 2 ) pre-testing and post-testing; and 3 ) experimental and control group, where study subjects are randomly assigned. A quasi- 
experimental study is not as rigorous as a classical experiment in manipulating the variables. It lacks key elements such as pre- and post-testing and/or control groups (Babbie, 2012).

- Methodological design - a framework or a paradigm, usually associated with a particular research purpose or a philosophy. A methodological design determines the specificity of using research methods for gathering and interpreting data. For example, the Delphi study design seeks to generate consensus from a panel of experts through iterations of questionnaire. This design determines how the research method, survey, is used to collect data from study participants.

\begin{tabular}{|l|l|c|}
\hline \multicolumn{2}{|c|}{$\bullet \quad$ Research Design } & $\begin{array}{l}\text { \# of articles that employed } \\
\text { the research design }\end{array}$ \\
\hline Time dimension & Longitudinal & 4 \\
\hline Degree of variable manipulation & Experimental design & 8 \\
\cline { 2 - 3 } & Quasi-experimental design & 6 \\
\hline Methodological design & Usability study & 10 \\
\cline { 2 - 3 } & $\begin{array}{l}\text { Case study and multiple-case } \\
\text { study }\end{array}$ & 4 \\
\cline { 2 - 3 } & $\begin{array}{l}\text { Evaluation research, } \\
\text { including outcome evaluation } \\
\text { and formative evaluation }\end{array}$ & \\
\cline { 2 - 3 } & Phenomenography & 3 \\
\cline { 2 - 3 } & Contextual inquiry & 2 \\
\cline { 2 - 3 } & Naturalistic inquiry & 1 \\
\cline { 2 - 3 } & Critical incident technique & 1 \\
\cline { 2 - 3 } & Participatory action research & 1 \\
\cline { 2 - 3 } & Grey relational analysis & 1 \\
\hline
\end{tabular}

Table 4. Research design employed in the primary research articles

\subsection{Theories/models}

Although JAL focuses on applied research that has direct implications on professional practice in academic libraries, a small number of articles involved theories or models to inform their study design or interpretation of data. A theory is an integrated set of propositions that serves as an explanation for a phenomenon, while a model, in contrast, is typically used to frame and represent processes and not to explain them, and it provides a plan for investigating and/or addressing a phenomenon (Guest \& Namey, 2014). As shown in the list below, most of the theories and models originated from fields outside of LIS, such as education, psychology, and business.

- Models:
o Platform market model
o Change management models
o Mintzberg's organizational model
o Models of information seeking and searching behavior
o Key Mediating Variable (KMV) model of relationship marketing
o Birnbaum's four models of higher education organizations
o Comprehensive allocation process (CAP) 
o The Kirkpatrick 29 evaluation model

o Community of practice model

o Quality function deployment (QFD) - Kano model

o Market orientation model

o Richard N. Foster's technology S curves

o Competing values framework (CVF)

- Theories:

o Sense of community theory

o Disconfirmation theory

o Constructivist theory

o Activity theory

o Critical literacy theory

o HRM job satisfaction theory

\section{Discussion}

The content analysis of peer-reviewed JAL articles in the past decade provides an in-depth examination of academic library research and yields an enriched understanding of academic librarians' research engagement and output. Overall, academic librarians are making active contribution to scholarly communications - more than three-fourths of the JAL articles included at least one librarian author, which is much higher than findings from previous studies (Krausse \& Sieburth; Watson, 1985, Weller, Hurd and Wiberley, 1999; Wiberley, Hurd \& Weller , 2006), where only 40 to $50 \%$ of LIS journal articles were authored by academic librarians.

Collaboration is popular among JAL authors. More than half of the articles were coauthored. The co-authorship also showed great heterogeneity in that close to $40 \%$ of the coauthors were from different institutions, and more than one fourth of the collaboration was between librarians and nonlibrarians. Even though co-authorship does not necessarily lead to higher quality articles (Hart, 2007), research collaboration is highly recommended because of its benefits: 1) collaboration enables researchers to share skills and techniques, and is one way of transferring knowledge (especially tacit knowledge); 2) through clashing views it may bring about the cross-fertilization of ideas, which may in turn generate new insights or perspective that individuals, working on their own, would not have grasped; 3) collaboration provides intellectual companionship (e.g. within a practicing community); 4) collaboration plugs the researcher into a wider contact network in the scientific community; and 5) it enhances the potential visibility of the work (Sitienei \& Ocholla, 2010). A frequently cited motivation for research collaboration is the nature of the research problem (Luo, 2013). Thus, to encourage more collaboration among librarians, it will be helpful to create opportunities for them to recognize research issues that could benefit from a collaborative approach. Such opportunities may involve offering a forum for them to exchange research ideas and explore potential collaboration. One idea is to invite successful collaborative researchers to share their experience and lessons. Another is to provide venues where librarians and their potential collaborators (e.g. faculty members) can meet and converse about their research. For example, Laprise and Thivierge (2012) discussed the innovative approach of using speed dating sessions to foster collaboration among medical professionals. A 35-minute speed dating session was carried out during a 2-hour faculty development workshop, and the majority of the participants 
were satisfied with it and believed that the method was a stimulating and efficient way to meet new colleagues, quickly share clinical issues and goals, and identify opportunities for collaboration. Future research is also needed to further investigate librarian authors' collaborative experience in order to make suggestions on best practices in research collaboration.

Almost two-thirds of the articles were primary research articles, which are important to generating original data to inform decision making and improve professional practice. In Luo's (2011) study about the role of research methods education in fusing LIS research into practice, she found that $77.4 \%$ of the librarians read scholarly publications and apply research findings to improve work. Therefore, it is critical for journals such as JAL to continue the emphasis on primary research and publishing articles that could have far-reaching impact on academic library work.

JAL's articles covered a wide variety of topics, and information literacy was the most prevalent one, followed by user information behavior, library personnel, scholarly communications, and twenty other topics. The topical coverage distribution exhibits the varying popularity of the different research domains. Based on the comparative analysis of the top four topics, there is no identifiable trend over the past decade. However, it would be interesting to have a historical view of how the topics have evolved in the past few decades. Unfortunately, there are no studies providing a comprehensive examination of published topics specifically related academic library research in previous decades. Future research may focus on this area and document the longitudinal shift of research interests and emphases among academic librarians.

Regarding the research methods and research design of the articles, survey and content analysis were the two most popular methods for data collection/analysis. This understanding of how academic librarians design and conduct their studies will have practical implications in establishing effective research education and training programs for academic librarians. To foster the research culture among librarians and encourage them to conduct research, two sources of support are usually needed: administrative support at work, and more importantly, research training/education. Stoan (1984) pointed out that offering formal research training/education can enhance librarians' understanding and appreciation of the practical value of research and equip them with necessary knowledge/skills to interpret/conduct research to solve problems at work. In research training programs such as IRDL, emphasis may be given to survey research and content analysis due to their popularity in academic library research. For example, survey may be a convenient and useful research method, especially for researchers with scarce research funds, but it does not necessarily mean that it is always used properly. Babbie (2012) opined that the "broad proliferation of unclear and ambiguous questions in surveys" ( $p$. 256) makes it important for surveyors to systematically study how to construct a survey questionnaire and administer it to gather meaningful and actionable data. Therefore, in research education/training programs, adequate coverage should be arranged for this frequently used but easily misused method in academic library research.

Another interesting discovery in the study is the theories and models applied in a small number of articles - these theories and models mostly come from fields outside of LIS, indicating that academic library research has interdisciplinary potential and such potential could be nurtured to produce more interdisciplinary research and introduce more fresh perspectives. Interdisciplinary research is defined as "any study or group of studies undertaken by scholars from two or more distinct scientific disciplines. The research is based upon a conceptual model that links or integrates theoretical frameworks from 
those disciplines, uses study design and methodology that is not limited to any one field, and requires the use of perspectives and skills of the involved disciplines throughout multiple phases of the research process" (Aboelela et al., 2006, p. 340). Ample evidence can be found in the literature that provides a strong conceptual justification for interdisciplinary studies and promote the institutional and societal benefits of such research, including increased density of various relationship networks and research productivity (Klein, 1996; Armstrong, 2006; Kessel, Rosenfield \& Anderson, 2008; Repko, 2008; Haines, Godley \& Hawe, 2011; Kodama, Watatani \& Sengoku, 2013). Successful interdisciplinary research is usually contingent upon five factors: locus of interdisciplinary (the way in which interdisciplinarity is situated within a research team), catalysis (deliberate steps to achieve integration and coherence), inspiring leadership, active management, and continuous learning and capacity building (Lyhall, Bruce, Marsden \& Meagher, 2013). Academic librarians, if interested in fostering an interdisciplinary culture and developing interdisciplinary relationships, should further explore the five factors.

\section{Conclusion}

This study delivers a comprehensive analysis of the peer-reviewed articles published in JAL in the past decade, examining key variables such as article type, authorship, topic, research methods/design, and theories/models. An aggregated view about a decade's worth of academic library research is provided, enabling an enriched understanding of academic librarians' research engagement and output. Ultimately, results of the study will inform the curricular design and pedagogy in research training/education for academic librarians, and contribute to the enhancement of research culture and research practice among them. For future research, the authors hope to expand the content analysis to other important outlets for academic library research (e.g. College and Research Libraries) and further examine the published research on topics related to academic library.

\section{References}

Aboelela, S., Larson, E., Bakken, S., Carrasquillo, O., Formicola, A., Glied, S., Haas, J., \& Gebbie, K. (2007). Defining interdisciplinary research: Conclusions from a critical review of the literature. Health Services Research, 42(1), 329-346.

Armstrong, P. (2006). Advancing interdisciplinary health research: A synergism not to be denied. Canadian Medical Association Journal, 175(7), 761.

Babbie, E. (2012) The Practice of Social Research. Belmont, CA: Wadsworth Publishing.

Bandyopadhyay, A. (2013). Measuring the disparities between biology undergraduates' perceptions and their actual knowledge of scientific literature with clickers. Journal of Academic Librarianship, 39(2), 194-201.

Bobish, G. (2011). Participation and pedagogy: Connecting the social web to ACRL learning outcomes. Journal of Academic Librarianship, 37(1), 54-63. 
Bodi, S. (2002). How can we bridge the gap between what we teach and what they do? Some thoughts on the place of questions in the process of research. Journal of Academic Librarianship, 28,109-114.

Budd, J. \& Seavey, C. (1990). Characteristics of journal authorship by academic librarians. College \& Research Libraries, 51(5), 463-470.

Cusker, J. (2013). Elsevier Compendex and Google Scholar: A quantitative comparison of two resources for engineering research and an update to prior comparisons. Journal of Academic Librarianship, $39(3), 241-243$.

Dubose, S. \& Durant D. (2001). Research and practice in academic libraries: A case study. North Carolina Libraries, 59, 4-9.

Fister, B. (1992). The research processes of undergraduate students. Journal of Academic Librarianship, $18,42-43$.

Fister, B. (1993). Teaching the rhetorical dimensions of research. Research Strategies, 11, 211-219.

Greer, K., Swanberg, S., Hristova, M., Switzer, A. \& Daniel, D. (2012). Beyond the Web tutorial: Development and implementation of an online, self-directed academic integrity course at Oakland University. Journal of Academic Librarianship, 38(5), 251-258.

Guest, G. \& Namey, E. (2014). Public Health Research Methods. Thousand Oaks, CA: Sage Publications.

Haines, V., Godley, J., \& Hawe, P. (2011). Understanding interdisciplinary collaborations as social networks. American Journal of Community Psychology, 47, 1-11.

Hahna, J. \& Morales, A. (2011). Rapid prototyping a collections-based mobile wayfinding application. Journal of Academic Librarianship, 37(5), 416-422.

Hart, R. (2007). Collaboration and article quality in the literature of academic librarianship. Journal of Academic Librarianship, 33(2), 190-195.

Hernon, P. \& Schwartz, C. (1995). Can research be assimilated into the soul of library and information science? Library and Information Science Research, 17, 101-103.

Institute of Museum and Library Services. (2013). IMLS library services September 2013 grant announcement. Retrieved from http://www.imls.gov/news/2013 ols grant announcement.aspx

Jarvis, P. (1999). The Practitioner-Researcher: Developing theory from practice. San Francisco, CA: JosseyBass Publishers.

Kessel, F., Rosenfield, P., \& Anderson, N. (2008). Interdisciplinary research: Case studies from health and social science. New York, NY: Oxford University Press. 
Klein, J. T. (1996). Crossing boundaries: Knowledge, disciplinarities, and interdisciplinarities. Charlottesville, VA: University Press of Virginia.

Kodama, H., Watatani, K., \& Sengoku, S. (2013). Competency-based assessment of academic interdisciplinary research and implication to university management. Research Evaluation, 22, 93104.

Krausse, S. C. \& Sieburth, J. F. (1985). Patterns of authorship in library journals by academic librarians. Serials Librarian, 9(3), 127-138.

Laprise, R. \& Thivierge, R. (2012). Using speed dating sessions to foster collaboration in continuing interdisciplinary education. Journal of Continuing Education in the Health Professions, 32(1), 24-30.

Lenox, M. F. (1985). The importance of using research for decision making. Top of the News, 301-302.

Lyall, C., Bruce, A., Marsden, W., \& Meagher, L. (2013). The role of funding agencies in creating interdisciplinary knowledge. Science and Public Policy, 40, 62-71.

Luo, L. (2011). Fusing research into practice: The role of Research Methods education. Library and Information Science Research, 33(3), 191-201.

Luo, L. (2013). Being interdisciplinary: A look into the background and experiences of iSchool faculty members. LIBRES, 23(2), 1-20.

Mahraj, K. (2012). Reference Services Review: Content analysis, 2006-2011. Reference Services Review, 40(2), 182-198.

Matsuoka-Motley, N. (2011). Librarian as commodity: Outsourcing in Japanese academic libraries. Journal of Academic Librarianship, 37(3), 273-277.

Montanelli, D. \& Stenstrom P. E. (1986). The benefits of research for academic librarians and the institutions they serve. College \& Research Libraries, 47(5), 482-485.

Neyer, L. \& Yelinek, K. (2011). Beyond boomer meets NextGen: Examining mentoring practices among Pennsylvania academic librarians. Journal of Academic Librarianship, 37(3), 215-221.

Ocholla, D., Ocholla, L., \& Onyancha, O. B. (2012). Research visibility, publication patterns and output of academic librarians in sub-Saharan Africa. Aslib Proceedings: New Information Perspectives, 64(5), 478-493.

Perkins, G. H. \& Helbig, T. (2008). The value of LIS schools' research topics to library authors' professional work. Journal of Academic Librarianship, 34(6), 513-519.

Perkins, G. H. \& Slowik. (2013). The value of research in academic libraries. College \& Research Libraries, 74(2), 143-158. 
Powell, R. R., Baker, L. M., \& Mika, J. J. (2002). Library and information science practitioners and rsearch. Library and Information Science Research, 24, 49-72.

Repko, A. (2008). Interdisciplinary research: Process and theory. Thousand Oaks, CA: Sage.

Shupe, E. \& Pung, S. (2011). Understanding the changing role of academic librarians from a psychological perspective: A literature review. Journal of Academic Librarianship, 37(5), 409-415.

Sitienei, G. \& Ocholla, D. (2010). A comparison of the research and publication patterns and output of academic librarians in eastern and southern Africa from 1990-2006: A preliminary study. South African Journal of Libraries and Information Science, 76(1), 36-48.

Stephens, J., Hubbard, D., Pickett, C. \& Kimball, R. (2013). Citation behavior of aerospace engineering faculty. Journal of Academic Librarianship, 39(6), 451-457.

Stewart, C. (2010). Whither metrics? Tools for assessing publication impact of academic library practitioners. Journal of Academic Librarianship, 36(5), 449-453.

Stewart, C. (2011). Whither metrics, part II. Tools for assessing publication impact of academic library practitioners. Journal of Academic Librarianship, 37(5), 445-448.

Stoan, S. K. (1984). Research and library skills: an analysis and interpretation. College \& Research Libraries, 45, 99-109.

Tang, Y. (2013). Distance education librarians in the United States: A study of job announcements. Journal of Academic Librarianship, 39(6), 500-505.

Watson, P. (1985). Production of scholarly articles by academic librarians and library school faculty. College \& Research Libraries, 46(4), 334-342.

Weller, A. C., Hurd, J. M., \& Wiberley, S. E. (1999). Publication patterns of U.S. academic librarians from 1993-1997. College \& Research Libraries, 60(4), 352-362.

Wiberley, S. E., Hurd, J. M., \& Weller, A. C. (2006). Publication patterns of U.S. academic librarians from 1998-2002. College \& Research Libraries, 67(3), 205-216. 